\title{
Surgical stress response and promotion of metastasis in colorectal cancer: A Complex and Heterogeneous process.
}

\author{
Corina Behrenbruch ${ }^{1,2}$, Carolyn Shembrey ${ }^{1}$, Sophie Paquet-Fifield ${ }^{1}$, Christina Mølck $^{1}$, Hyun-Jung Cho $^{3}$, Michael
} Michael $^{4}$, Benjamin N.J. Thomson ${ }^{2,5}$, Alexander G. Heriot ${ }^{2}$, and Frédéric Hollande ${ }^{1^{*}}$

${ }^{1}$ The University of Melbourne, Department of Pathology, Victorian Comprehensive Cancer Centre, 305 Grattan St Melbourne 3000, Australia

${ }^{2}$ Division of Cancer Surgery, Peter MacCallum Cancer Centre, Victorian Comprehensive Cancer Centre, 305 Grattan St, Melbourne 3000, Australia

${ }^{3}$ The University of Melbourne, Biological Optical Microscopy Platform, Medical Building, Grattan Street, Parkville 3010, Australia

${ }^{4}$ Division of Cancer Medicine, Peter MacCallum Cancer Centre, Victorian Comprehensive Cancer Centre, 305 Grattan St, Melbourne 3000, Australia

${ }^{5}$ The University of Melbourne, Department of Surgery, Royal Melbourne Hospital, 300 Grattan St Parkville 3000, Australia.

* Corresponding author: Department of Pathology, University of Melbourne Centre for Cancer Research, The University of Melbourne, Victorian Comprehensive Cancer Centre, Level 10, 305 Grattan Street, Melbourne, VIC3000 Australia. Email: frederic.hollande@unimelb.edu.au

Article type: Special Issue: Treatment-induced metastasis

Keywords: Surgical stress; Metastatic Heterogeneity; Lentiviral Gene Ontology Vectors; Adrenergic signaling; RGB labeling

Abbreviations: COX-2 (cyclooxygenase 2); $\beta$-AR (beta-adrenergic receptor); CRP (C-reactive protein); Tregs (regulatory T-cells); CTCs (circulating tumor cells); ctDNA (circulating tumor DNA); VEGF (Vascular endothelial growth factor); MMP (Matrix Metallo-proteinase); DPC (digital phase contrast).

Conflict of Interest: The authors have no conflict of interest in relation with this manuscript.

\section{ABSTRACT}

Surgery remains the curative treatment modality for colorectal cancer in all stages, including stage IV with resectable liver metastasis. There is emerging evidence that the stress response caused by surgery as well as other perioperative therapies such as anesthesia and analgesia may promote growth of pre-existing micro-metastasis or potentially initiate tumor dissemination. Therapeutically targeting the perioperative period may therefore reduce the effect that surgical treatments have in promoting metastases, for example by combining $\beta$-adrenergic receptor antagonists and cyclooxygenase-2 (COX-2) inhibitors in the perioperative setting. In this paper, we highlight some of the mechanisms that may underlie surgery-related metastatic development in colorectal cancer. These include direct tumor spillage at the time of surgery, suppression of the anti-tumor immune response, direct stimulatory effects on tumor cells, and activation of the coagulation system. We summarize in more detail results that support a 
role for catecholamines as major drivers of the pro-metastatic effect induced by the surgical stress response, predominantly through activation of $\beta$-adrenergic signaling. Additionally, we argue that an improved understanding of surgical stress-induced dissemination, and more specifically whether it impacts on the level and nature of heterogeneity within residual tumor cells, would contribute to the successful clinical targeting of this process. Finally, we provide a proof-of-concept demonstration that ex-vivo analyses of colorectal cancer patient-derived samples using RGB-labeling technology can provide important insights into the heterogeneous sensitivity of tumor cells to stress signals. This suggests that intra-tumor heterogeneity is likely to influence the efficacy of perioperative $\beta$-adrenergic receptor and COX-2 inhibition, and that ex-vivo characterization of heterogeneous stress response in tumor samples can synergize with other models to optimize perioperative treatments and further improve outcome in colorectal and other solid cancers. 


\section{INTRODUCTION}

Colorectal cancer (CRC) is the third highest cause of cancer-related death in the developed world [1], and surgery remains essential for curative treatment in colorectal cancer across all stages. Despite oncologically-sound surgical techniques and removal of tumor and draining lymph nodes, disease progresses in a significant number of patients. Metastatic disease from colorectal adenocarcinoma most commonly develops in the liver, peritoneum, lung and bone via either haematogenous, lymphatic or transceloemic spread. The series of steps involved in metastatic progression are modified both by the intrinsic properties of the tumor cells and by the host response [2]. There is emerging evidence that surgery itself and associated complications, as well as perioperative adjuncts such as anesthesia and analgesia, may promote metastatic development either through direct effect on tumor cells or by acting on the tumor microenvironment, including on the immune system[3]. Multiple steps in the metastasis initiation pathway may be influenced by surgery, which may play a role in subsequent disease relapse by promoting minimal residual disease, either through tumor spillage during surgery or by promoting growth of micro-metastases disseminated prior to surgery that were not identified during pre-operative imaging [4]. In particular, excessive release of catecholamines is thought to be a major driver of the pro-metastatic effect induced by the surgical stress response, predominantly through the $\beta 2$-adrenergic receptor[5]. The amplitude and duration of response correlate with the extent of surgical injury and are influenced by associated complications (e.g. sepsis). Yet, their correlation with clinical outcome is less clear, with some animal studies suggesting a correlation between the magnitude of surgical stress and the number of metastatic deposits that develop[6,7], while other animal studies as well as results in humans indicate that this is not always the case[3]

Studying the effect of the operative and post-operative period on the promotion of metastasis is challenging due to difficulty designing experiments in humans, with much of the current data coming from animal models and from extrapolation of clinical data in humans. This is in part due to the complexity of surgery-induced stress and the difficulty in analyzing its impact in isolation. Indeed, a significant number of perioperative procedures may also promote metastasis, including administration of anesthetic agents, analgesics and blood transfusions. Physiological

changes due to surgery such as hypothermia, fasting, pain and psychological stress may also contribute to the total surgical stress response. Other post-operative complications such as infection not only exacerbate the surgical stress 
response but may result in delay of adjuvant chemotherapy, which is generally given within 6-8 weeks after surgery in colorectal cancer to gain maximal oncological benefit[8]. Surgical stress may also impact on the metabolism of cytotoxic agents through its impact on drug metabolism and membrane transport, [9,10], although this is beyond the scope of this review $[9,10]$.

It is therefore surprising that there are no standard perioperative anti-cancer therapies given to cancer surgery patients to minimize the stress response. There is however increasing interest in targeting the unique operative and perioperative period to modulate metastasis-promoting effects [3]. This includes a recent randomized trial that tested the combination of a $\beta$-adrenergic receptor antagonist and cyclooxygenase-2 (COX-2) inhibitor during the perioperative setting in breast cancer patients. Perioperative treatment with propranolol and etolodac showed decreased epithelial-to-mesenchymal transition, reduced activity of pro-metastatic/pro-inflammatory transcription factors, decreased tumor-infiltrating monocytes and normalization of pre-surgical elevation in serum interleukin-6 (IL-6) and C-reactive protein levels (CRP) [11]. In this manuscript, we will further discuss the mechanisms involved in surgery-mediated metastasis, outline therapeutic strategies proposed to reduce the pro-metastatic effect of the surgical stress response, and present a novel approach to analyze the heterogeneous response of tumor cells to the surgical stress response.

\section{Pro-metastatic Effects of Surgery}

As summarized in Figure 1, a number of concomitant mechanisms may account for the demonstrated pro-metastatic effect of surgery, including direct spillage of tumor cells during the surgical procedure, suppression of the antitumor immune response or promotion of tumor cell proliferative and/or invasive capacities.

\section{1-Tumor spillage}

The most direct mechanism of increased metastatic dissemination following surgery is linked to tumor spillage and to a resulting increase in circulating tumor cell burden during surgical resection through manipulation of the tumor, involvement of margins with R1 or R2 resection (where tumor cells remain microscopically or macroscopically detectable, respectively, at the edge of resected tissues), and rupture or breach of tumor during surgery[12]. The 
result is contamination of the lymphatics and/or veins that drain the tumors, as well as spillage of tumor deposits within the peritoneal cavity. Current data suggests that the presence of circulating tumor cells (CTCs) and circulating tumor DNA (ctDNA) at the time of CRC surgery correlates with poorer patient outcomes, although further and more robust studies are required[13]. Additionally the genetic makeup of residual tumors has been found to be modified following surgery in non-small cell lung cancer, with variation of mutation frequency within ctDNA in pre vs. post-operative samples [14].

To date, strategies to combat tumor spillage/emboli have predominantly focused on the implementation of strict oncological surgical techniques including 'en bloc' resection, minimal handling of tumors, usage of wound edge protectors, complete mesenteric excision, adequate surgical margins (proximal and distal) and proximal vascular ligation[15]. Additionally, patients may receive adjuvant chemotherapy and radiotherapy to prevent disease recurrence[16]. There are other more novel techniques not used routinely that have shown benefit in reducing metastasis such as humidification of carbon dioxide used during laparoscopy[17] and instillation of tumoricidal agents at the completion of surgery[18,19]. Additional experimental strategies aim to reduce peritoneal tumor adhesion through targeting of specific adhesion molecules or extracellular matrix binding proteins (e.g. integrins) [12]. For example, the intra-peritoneal instillation of heparin was shown to reduce ICAM-1 expression and thereby drastically decrease tumor-mesothelial cell adhesion in rats[20].

\section{2 - Suppression of Cell Mediated Immunity}

Surgery for resection of either primary colorectal cancer or its metastasis leads to a profound inflammatory response as it generally involves extensive dissection, use of energy devices and potential spillage of bowel contents that may worsen the inflammatory response [21]. Intra-abdominal surgery triggers a significant inflammatory response particularly due to trauma of the peritoneum, which has numerous biological functions in the regulation of inflammation, fibrinolysis and angiogenesis[22]. Interestingly, whether they are surgery-related or not, inflammatory responses may not always promote tumor progression, as acute infection and stimulation of immune effectors have been reported to sometimes drive 'spontaneous' regression of cancer[23]. Spontaneous regression can also occur in the setting of pharmacologically-induced immune-stimulation such as after Rose Bengal injection in in-transit 
melanoma[24]. Although the reasons that determine whether inflammation induces tumor regression or drives progression remain poorly understood, it is probable that the nature of the inflammatory triggers and the subsets of immune cells involved play a major role in this process.

The extent of post-surgical inflammation and the downstream modulation of the cell-mediated immune response appear to vary depending on whether the surgical approach chosen to resect colorectal tumors is 'minimally invasive' (laparoscopic, robotic) or based on traditional open techniques. Yet, although several human studies have shown reduction in stress response [25-27], better preservation of cell-mediated immune response [28] and faster postoperative immunological recovery[29] in laparoscopic and robotic surgery compared to the traditional open technique [25-27], the resulting consequences on patient survival remain a matter of debate. Several clinical trials have sought to compare the oncological outcomes between laparoscopic and open surgery. The only available longterm outcome data comes from the CLASSIC trial, with 10-year results showing equivalent disease-free and overall survivals between laparoscopic and open surgery groups [30]. Other trials have so far shown equivalent 3-year survival (COLOUR II, COREAN) or equivalent resection quality (ALaCaRT) between laparoscopic and open surgery, but their long-term survival outcome data is not yet available. Interestingly, analysis of the systemic and peritoneal cytokines levels following surgery suggest it is the peritoneal wound or intraperiteonal dissection that is more predictive of the stress response than the skin incision, which suggests that the use of a laparoscopic technique does not necessarily mean that it will be minimally invasive $[31,32]$.

If the surgical trauma is significant and locally-produced inflammatory mediators spill into the systemic circulation, a significant stress response occurs. The key components of this response include activation of the sympathetic nervous system, an increase in secretion of pituitary hormones and hematological changes including cytokine production and the acute phase reaction[6]. The excessive release of catecholamines and prostaglandins has been shown to strongly affect the cell-mediated immune response, acting via the modulation of several immune cell subtypes. Thus, following colorectal cancer surgery, the number of circulating CD4+ and CD8+ T lymphocytes has been reported to significantly decrease [33]. While the amount and activation of circulating T lymphocytes do not always reflect those found within tumors, this result is nevertheless in agreement with the instrumental role of 
infiltrating tumor lymphocytes in the control of tumor progression[34]. In addition, cytokine production has been reported to increase after colorectal cancer surgery [35] and to shift the Th1/Th2 lymphocyte balance in favor of Th2 cells $[36,7,37]$. The innate immune response is also altered, as shown by the suppression of natural killer (NK) cell counts in CRC patients following surgical resection of liver metastases or other types of cancer surgery procedures [38]. The association with NK cells and improved survival in patients with colorectal liver metastasis is still controversial as some studies of resected specimens have shown NK cell infiltration is associated with improved survival while others were unable to demonstrate this association $[39,40]$. Nevertheless, promoting NK cell mediated immune responses in the peri-operative period may also have beneficial effects for CRC patient survival, as shown in animal models of liver metastasis[41-43].

The emergence of immune-therapy as a highly exciting advance in cancer therapy suggests that promoting an antitumor immune response in the peri-operative period may inhibit tumor progression and thereby yield very positive survival outcomes. Although no peri-operative immunogenic treatments are currently used clinically, several animal and human studies have investigated their potential role in the control of minimal residual disease. Promoting NK cell mediated immune responses has been shown to suppress liver metastasis in animal models[41-43]. Two reports in the 1980s showed reduction of colorectal liver metastasis development in rats after portal venous injection of tumor cells with subsequent administration of immunogenic compounds levamisole and human recombinant interleukin-2 (IL-2), an immune-stimulant of NK cells [44,45]. A later trial in the 1990s Administration of low dose recombinant IL-2 to 12 patients undergoing colorectal cancer resections was reported to prevent the post-operative fall in NK cells and to induce in vivo T-cell activation, as shown by up-regulation of the subset marker CD25 (IL-2 receptor) and CD45RO cells (T-memory cells)[46]. In 2007 a case control study compared 67 patients treated with 6 doses of IL-2 4 days prior to colorectal cancer surgery. After a median follow-up of 69 months (range: 12-169) the progression rate was lower in treated patients than in controls $(15 / 67,22 \%$ vs $68 / 173,39 \%$; $=0.02)[47]$. Alternatively some studies succeeded in inhibiting surgically-induced NK dysfunction using vaccines such as influenza and oncolytic vaccinia virus (mice and humans), albeit on small numbers of patients or animals [48,7]. It will be interesting to see if future research will include use of newer immunotherapy agents such as CTLA-4 and PD-1 inhibitors. 


\section{3 - Direct stimulation of tumor cells}

Peri-operative release of catecholamines and prostaglandins is thought to be a major contributor to the surgical stress response[3]. Interestingly, COX-2 expression is upregulated in many human malignant and pre-malignant tumors, especially colorectal and mammary carcinomas [49]. While stress-induced effects clearly involve a modulation of the anti-tumor immune response[50], they are also due at least in part to the direct stimulation of tumor cell proliferation or invasion, for example through $\beta$-adrenoreceptor ( $\beta$-AR) activation[51]. Additionally, adrenaline and noradrenaline have been shown to enhance migration and invasion, to reduce anoikis and apoptosis, and to increase the secretion of VEGF, MMP2/9 and IL6 and 8 in vitro in a number of cell lines[49,52,3]. In a recent review expression of both $\beta 1$ - and $\beta 2$-AR (mRNA and protein levels) has been repeatedly detected across several cancer types. In particular, colorectal cancer cell lines such as HT-29, SW116, SW480 and LS174 were all shown to primarily express $\beta 2$-AR mRNA. $\beta 1$ - and $\beta 2$-AR appear to mediate the proliferative effects of adrenergic agonists, and signaling pathway activated in response to stimulation of $\beta$-ARs mostly involved ERK1/2 in colorectal cancer cells[51]. Additionally, $\beta 2$-ARs were shown to regulate growth in colorectal xenograft models, by controlling an EGFR-Akt/ERK1/2 signaling axis and thereby altering the balance between tumor cell proliferation and apoptosis[53]. In other tumor types, such as breast cancer, $\beta$-AR stimulation has been shown to both stimulate and inhibit growth, with no clear reason for this discrepancy nor clear correlation with the level of $\beta 2$-AR expression[54]. These findings suggest that, while this may not be as clear in other cancers, $\beta 2$-adrenergic stimulation clearly promotes tumor progression in colorectal cancer.

This has implications when assessing the potential of $\beta$-AR antagonists to be used during the perioperative period to reduce the pro-metastatic effect of surgery. A recent study by Sorski et al. (2016) showed that blocking excess prostaglandin and catecholamines during surgery in mice with the COX-2 inhibitor etolodac and $\beta$-AR antagonist propranolol reduced experimental liver metastasis in the syngeneic CT26 colon cancer model[50]. Other studies have shown synergism between COX-2 inhibitors and $\beta$-AR antagonists, both acting via modulation of cAMP production $[55,49,36]$. Promising results have emerged from a phase II randomized clinical trial in breast cancer patients, suggesting that perioperative inhibition of $\beta$-AR and COX-2 signaling (using propranolol and etodolac, respectively) had beneficial effects on the expression of clinically-relevant metastatic biomarkers[11]. In addition, a current multicenter- randomized clinical trial is in progress (NCT00888797) to assess the effect of tumor recurrence 
and post-operative immune perturbations following the perioperative administration of a $\beta$-AR antagonist and a COX2 inhibitor in patients undergoing resection for primary colon and rectal cancer[3].

\section{4 - Activation of the coagulation system}

Malignancy itself is well known to promote a hypercoagulable state, both due to the production and release of procoagulant compounds by tumor cells as well as to their interaction with other blood cells such as platelets which may result in enhanced activation of platelets or thrombocytosis [56]. In fact, pre-operative thrombocytosis in stage II colorectal cancer is an indicator of poor cancer-specific and disease-free survival. Surgery itself can lead to activation of the coagulation pathway, both directly due to endothelial and peritoneal damage and indirectly via the acute phase or inflammatory response, which includes release of pro-inflammatory cytokines such as IL-1 and IL-6 and tumor necrosis factor (TNF) [57]. This results in tissue factor-mediated thrombin generation, downregulation of physiological anticoagulant mechanisms such as those involving Protein $\mathrm{C}$ and $\mathrm{S}$, inhibition of fibrinolysis due to elevated levels of PAI-1 and thrombocytosis [58,59]. The resulting hypercoagulable state promotes metastasis via a number of mechanisms. The formation of microthrombi (containing platelets and fibrin) around tumor cell emboli has been shown to promote tumor adherence as well as to shield tumor cells from clearance by natural killer cellmediated destruction, particularly once tumor cells have entered the blood stream. [60,61].

Since aspirin inhibits platelet function and increases fibrinolysis, a number of trials are investigating the role of aspirin in the post-operative setting in preventing future metastasis. This includes a Phase-3 Chinese study APREMEC, specifically for colorectal cancer, as well as ADD-ASPIRIN, a multicenter trial in the UK assessing the effect of aspirin in a several solid tumors [62]. Currently, following major intra-abdominal surgery a standard treatment is to receive prophylactic heparin (low molecular weight or unfractionated) to prevent post-operative thrombosis. In specific scenarios such as deep pelvic surgery (e.g. for rectal cancer), some medical centers

recommend extended venous thromboembolus prophylaxis for up to 6 weeks due to the prolonged risk of thrombosis, reflecting the fact that activation of the coagulation system can be prolonged following such surgery. Finally, a Canadian trial (PERIOP-01) is investigating the role of extended peri-operative treatment with tinzaparin, a heparin-related antithrombotic drug, to improve disease-free survival in patients with resectable colorectal cancer. 


\section{$\underline{\text { Pro-metastatic Effects of Adjunct Peri-operative Treatments and complications }}$}

Additional perioperative therapies and surgical complications that contribute to and increase the complexity of the surgical stress response include anesthetic agents, analgesics, blood transfusions, hypothermia and prolonged fasting. With respect to anesthesia, pre-clinical data suggest that beneficial approaches might include selection of induction drugs such as propofol, minimizing the use of volatile anesthetics, and co-administration of cyclooxygenase antagonists with systemic opioids[63,64]. The use of thoracic epidural anesthetic results in significantly lower noradrenaline and cortisol concentration[65]. In addition epidural anesthesia reduces the need for post-operative opioids, which have been found to inhibit cell-mediated and humoral immunity, to promote tumor cell migration and proliferation, and to facilitate angiogenesis $[66,67]$. Blood transfusion has been shown to reduce the function of $\mathrm{T}$ helper and NK cells and to thus impair cell-mediated immune responses [68]. Additionally, stored blood with aged erythrocytes has been found in animal studies to be more harmful in the context of promoting metastasis[69]. Hypothermia, in addition to increasing blood loss through coagulopathy may also suppress NK cells. Strategies to combat hypothermia and to reduce the need for blood transfusion include pre-operative iron transfusions, warming patients prior to surgery and the use of humidified warmed $\mathrm{CO}_{2}$ during laparoscopy[70]. Prolonged fasting prior to surgery exacerbates the catabolic stress response, and enhanced recovery programs with reduced fasting, carbohydrate supplement drinks and glycemic control have shown a positive effect on stress response, including decreased IL6 and C-reactive protein (CRP) levels[71,72]. Such findings strongly support a tumor-promoting role for adjunct peri-operative treatments.

\section{Activation of Pro-Metastatic Pathways by Adrenergic Signaling - A Heterogeneous Process}

Multiple murine models have been used to study the impact of surgical stress on tumor progression and metastasis development in colorectal and other cancers [73,60,74]. However, these models do not establish whether all tumor cells are evenly sensitive to this type of stress stimulus, or if tumor cell subpopulations with vastly different sensitivity to stress signals co-exist within individual tumors. In the case of surgery-induced stress, while the characterization of $\beta$-adrenergic and prostaglandin-driven pro-metastatic effects has led to the emerging use of $\beta$-AR antagonists and/or COX-2 inhibitors in patients undergoing surgery[75], whether these compounds evenly target all tumor cells remains unknown. Considering the important levels of non-genetic cellular heterogeneity reported in 
multiple solid tumors and the profound impact this can have on therapy outcomes[76], developing models that allow access to this type of information is essential to fully understand the complexity and clinical impact of tumor stress responses. Indeed, higher levels of cellular heterogeneity within individual tumors correlate with higher posttreatment recurrence $[77,78]$ and poorer prognosis $[79,80]$ in several cancers including CRC. Therefore, understanding to which degree pro-metastatic surgical stress responses are heterogeneous would undoubtedly contribute to improve the efficacy of peri-operative medical treatment.

To determine whether catecholamines homogeneously affect all cells within individual patient tumors, we elected to use an ex-vivo approach on patient-derived colorectal cancer cells. We transduced these cells with Lentiviral Gene Ontology (LeGO) vectors (Figure 2a). This approach involves the labeling of individual tumor cells with cell populations with submaximal levels of three LeGO vectors encoding Red, Green and Blue (RGB) fluorescent proteins, respectively, resulting in subpopulations with stable and distinguishable color signatures [81]. Importantly the resulting fluorescent signature of each cell is carried through to its progeny, enabling the longitudinal monitoring of cell lineages over time under multiple conditions. We took advantage of this system to determine whether the response to pharmacological $\beta$-AR antagonists and COX-2 inhibitors was homogeneous or heterogeneous across individual tumor cell subpopulations from a patient-derived tumor sample.

We used RGB-tagged cells to quantify cell growth over a period of $48 \mathrm{~h}$ during in vitro treatment with the $\beta-\mathrm{AR}$ antagonist Propranol $(10 \mu \mathrm{M})$, the $\beta$-AR agonist Isoproterenol $(1 \mu \mathrm{M})$, and/or the COX-2 inhibitor celecoxib (1 $\mu \mathrm{M})$. The $\beta-\mathrm{AR}$ and COX-2 inhibitors were first tested in the absence of exogenous agonist. Concerning the $\beta-\mathrm{AR}$ pathway, this allowed us to account for potential off target effects of Propranolol, such as those reported for betablockers through the modulation of Pg-P expression[82,83]. In respect to COX-2 inhibition, celecoxib was used to inhibit the endogenous prostaglandin production by CRC cells. Indeed, confirming multiple prior studies by others in CRC cells[84-86], the patient-derived cells used in our experiments express significant levels of PTGS2 (COX-2), prostaglandin E2 synthase (PTGES2) and prostaglandin E2 receptor (PGTER2) mRNA (not shown), indicating that the PGE2 pathway is functional in these cells. 
We first observed that that $\beta-\mathrm{AR}$ and COX-2 blockade, respectively using a combination of Propranolol (10 $\mu \mathrm{M})$ and Celecoxib $(1 \mu \mathrm{M})$, induced a significant reduction $(\mathrm{p}<0.05$, two-way ANOVA with Tukey multiple comparison, $\mathrm{n}=3$ ) of overall tumor cell growth from $24 \mathrm{~h}$ onwards, while treatment of these cells with the $\beta-\mathrm{AR}$ agonist Isoproterenol $(1 \mu \mathrm{M})$ only had a non-significant stimulatory effect on tumor cell growth during the $48 \mathrm{~h}$ treatment (Figure 2b). Taking advantage of the fluorescent signature of RGB-tagged cells to monitor the growth behavior of multiple individual subpopulations, we found that the growth of vehicle-treated controls and Isoproterenol-stimulated cells was driven by a small number of predominant cell subpopulations (figure 2c-d) (e.g. subpopulations '111', '222', '444', cf supplemental Methods for details about subpopulation clustering and nomenclature). In addition, while the overall growth was strongly reduced in samples treated with Propranolol + Celecoxib (with or without Isoproterenol), several cell subpopulations (in particular '212') appeared unaffected by this treatment and demonstrated increased growth under these conditions (Figure 2e-f). Importantly, this subpopulation alone only represented $2.5 \%$ of the total cell sample, explaining why its growth behavior is largely undetectable when performing a sample-wide analysis. These results suggest that individual tumor cell subpopulations do show differential sensitivity to $\beta$-AR and COX-2 signaling, and indicate that RGB labeling offers a sensitive model to detect differential behaviors exhibited by minority cell subpopulations within complex tumor samples, that would otherwise remain undetected. Performing similar experiments on a large number of tumor samples and characterizing the molecular features of tumor cell subpopulations that may escape treatment with $\beta-$ AR antagonists and COX-2 inhibitors will unravel the full complexity of this process and bolster the development of new combination regimens to ensure that all tumor cell subsets are efficiently targeted.

We also used RGB-tagged cells to examine the motility of colorectal tumor cells for up to $48 \mathrm{~h}$ after mechanically disrupting a cell monolayer and treating these cells with $\beta$-adrenergic and COX-2 pharmacological modulators (Figure 3a). Under control (vehicle-treated) conditions we found that the average speed of individual subpopulations varied significantly, with the speed of highly motile subpopulations exceeding that of less motile ones by up to 3.5fold at the beginning of treatment, 2.3 -fold after $24 \mathrm{~h}$, and 1.8 -fold after $48 \mathrm{~h}$ (by which time cells were $>80 \%$ confluent) (Figure 3b-d, top graphs). Following treatment with $\beta$-adrenergic and COX-2 pharmacological effectors, population-wide motility was not significantly different from controls, but significant differences were detected 
when individual subpopulations were compared. Thus, rapid and transient stimulation of motility by Isoproterenol was observed in the case of subpopulations ' 312 ', '213' and ' 311 '. The average speed of cells from these subpopulations was strongly increased in the first 30 min after treatment, but minimal to no stimulation of these subpopulations was detected thereafter (Figure 3b-d). Importantly, we found that treatment with Propranolol + Celecoxib was not sufficient to block the Isoproterenol-induced motility activation for some of these subpopulations (e.g. ' 312 ', red bar in Figure 3b), and actually induced a paradoxical activation of motility for others ('112', '122', '412', '313', '413' 30 min after stimulation, or '212' after 48h, cf blue bars in Figure $3 \mathrm{~b}$ and 3d, respectively), which altogether represented less than $3 \%$ of the total cell numbers (Figure 3b-d). Interestingly, some of these subpopulations, such as '212', also displayed enhanced proliferation upon treatment with Propranolol and Celecoxib (Figure 2e-f), suggesting that they gained a significant competitive advantage under such conditions.

Taken together our findings revealed that different types of subpopulation-specific responses to stress induction are detectable within individual tumor samples using RGB-labeling technology. When using a clinically-relevant combination of $\beta-\mathrm{AR}$ antagonist and COX-2 inhibitor, we found that subpopulations with enhanced proliferation and/or motility emerged due to their apparent resistance to inhibition with these compounds. While the present experiments provide a clear proof-of-concept supporting the intra-tumor heterogeneity of pro-metastatic stress responses, specific identification of candidate sub-populations that may maintain or enhance their dissemination ability under $\beta-\mathrm{AR}$ and COX-2 blockade cannot be derived from our current results. Indeed, due to the complexity of simultaneously quantifying the motile behavior of more than sixty cells sub-populations under treatment, we cannot completely rule out the stochastic emergence and/or non-specific detection of some individual subpopulations that display differential behaviors. The purification and molecular characterization of identified subpopulations from multiple patient samples will determine which of these subpopulations represent genuine candidates and whether common molecular features can be detected that may underlie their differential sensitivity to stress-related signals. Nevertheless, comparison of sensitivities to $\beta$-AR agonist and inhibitor combination between individual cell subpopulations suggest that sensitivity to these compounds may be significantly heterogeneous in colorectal tumor samples, and our data suggests that RGB-labeling of tumor cell samples with LeGO vectors is a 
promising approach to refine our understanding of such heterogeneous behaviors.

\section{$\underline{\text { Conclusion }}$}

The observation that surgery may promote the progression of metastatic disease in cancer following removal of the primary tumor has been documented since the early 1900s [87]. Surgery for resection of either primary colorectal cancer or its metastasis leads to a profound inflammatory response as it generally involves extensive dissection, use of energy devices and potentially spillage of bowel contents that may worsen the inflammatory response[21]. A number of in vitro studies, conducted primarily on CRC cell lines, have identified and characterized the effect of stress hormones released during the systemic surgical stress response on colorectal tumor biology, with results demonstrating enhanced tumor cell proliferation and migration through $\beta$-AR activation due to excessive release of catecholamines $[88,51,89,90,52]$. The insight from in vivo mouse models of surgical stress, primarily obtained through studies in other cancer type has also contributed strongly to the field and enhanced our understanding of immune suppression mechanisms that enable stress-induced dissemination in CRC[73,74]. Advances in the field have highlighted the perioperative period as a unique window of opportunity to target multiple residual disease. This is firstly due to a disproportionately increased stress-induced metastasis risk but also due to the fact that adjuvant treatments such as chemotherapy and radiotherapy are generally not given during the perioperative period due to need for surgical recovery, implying that there is a period of time when minimal residual disease may be able to progress. Results presented here suggest that the role of intra-tumor heterogeneity on the tumor cell response to surgical stress should be further examined to help tailor these perioperative therapies, pre-empt dissemination by tumor cell subgroups with lesser sensitivity to $\beta$-AR and COX-2 inhibitors, and inform the design of additional compounds to further minimize the risk of metastatic dissemination.

\section{Acknowledgements}

The authors thank Dr. Erica Sloan for supplying the pharmacological compounds and acknowledge the financial support of CSSANZ and Covidien. They also wish to thank the University of Melbourne BOMP facility for their support with imaging experiments. 


\section{Figure legends:}

\section{Figure 1: Pro-Metastatic Effects of Surgery - Summary of Potential Mechanisms}

Figure 2: Heterogeneous growth response to pharmacological $\beta-\mathrm{AR}$ and/or COX-2 modulators in RGBtagged cells. CPP35 cells were derived from the primary colon adenocarcinoma (T4aN0M0) of an 81-year-old male patient using previously described protocols [91]. They were transduced with Lentiviral Gene Ontology (LeGO) vectors respectively encoding mCherry (Red), GFP (Green) and Cerulean (Blue) fluorescent proteins, under conditions described by others [81]. a: Representative microphotograph of RGB CPP35 cells (Scale bar: $100 \square \mathrm{m}$ ); b: Growth curves of RGB-tagged parental CPP35 cells treated for 48h with vehicle, Isoproterenol (1 $\mu \mathrm{M})$, Propranolol $(10 \mu \mathrm{M})+$ Celecoxib $(1 \mu \mathrm{M})$, or a mix of all three compounds at the above concentrations. Results are expressed as mean +/- SD of number of cells per field of view (FOV). (*, \#, p<0.05 vs. vehicle and Isoproterenol conditions, respectively; two-way ANOVA with Tukey's multiple comparisons, $\mathrm{n}=6$ fields of view from 3 experimental repeats); c-f: Growth curves of a representative selection of 9 individual subpopulations detected within RGB-tagged parental CPP35 cells, during a 48h treatment with vehicle (c), Isoproterenol (d), Propranolol + Celecoxib (e) or a mix of all three compounds (f), at concentrations shown under (b). Symbols representing each individual subpopulation are conserved in all graphs.

Figure 3: Heterogeneous motility response to pharmacological $\beta-\mathrm{AR}$ and/or COX-2 modulators in RGBtagged cells. CPP35 cells were derived and RGB-tagged as described in Figure 2. Cells were grown until $>70 \%$ confluent, then mechanically injured and stimulated with vehicle, Isoproterenol, Propranolol + Celecoxib, or a mix of all three compounds, as indicated. a: Digital Phase Contrast (DPC) and merged RGB fluorescence microphotographs of RGB CPP35 cells taken 30min, 24h and 48h following pharmacological treatment (Scale bars: $200 \mu \mathrm{m}$ ); b-d: Bar graphs representing the average migration speed (in Angstrom $(\AA) / \mathrm{sec}$ ) of individual tumor cell subpopulations over a 30-min measurement period, immediately (b), 24h (c) or 48h (d) after treatment with compounds described above. For each time point, the position of individual cell was tracked through measurement of position and of RGB fluorescence intensity every 5 min for 30 minutes, as detailed in supplemental Methods online. For each subpopulation, data are expressed as mean $+/-95 \%$ confidence interval from 25 to 800 cells per FOV per time point (the number of cells measured depends on the proportion of each subpopulation within the parental sample); ${ }^{*}, \mathrm{p}<0.05$ compared to the equivalent cluster in vehicle-treated cells, two-way ANOVA with Dunnett's multiple comparisons test; $n=3$ independent repeats. 


\section{References}

1. Bonjer HJ, Deijen CL, Abis GA, Cuesta MA, van der Pas MH, de Lange-de Klerk ES, Lacy AM, Bemelman WA, Andersson J, Angenete E, Rosenberg J, Fuerst A, Haglind E (2015) A randomized trial of laparoscopic versus open surgery for rectal cancer. N Engl J Med 372 (14):1324-1332. doi:10.1056/NEJMoa1414882

2. Talmadge JE, Fidler IJ (2010) AACR Centennial Series: The Biology of Cancer Metastasis: Historical Perspective. Cancer research 70 (14):5649-5669. doi:10.1158/0008-5472.CAN-10-1040

3. Horowitz M, Neeman E, Sharon E, Ben-Eliyahu S (2015) Exploiting the critical perioperative period to improve long-term cancer outcomes. Nature reviews Clinical oncology 12 (4):213-226. doi:10.1038/nrclinonc.2014.224

4. Nicoud IB, Jones CM, Pierce JM, Earl TM, Matrisian LM, Chari RS, Gorden DL (2007) Warm hepatic ischemiareperfusion promotes growth of colorectal carcinoma micrometastases in mouse liver via matrix metalloproteinase-9 induction. Cancer Res 67 (6):2720-2728. doi:10.1158/0008-5472.can-06-3923

5. Eng JW, Kokolus KM, Reed CB, Hylander BL, Ma WW, Repasky EA (2014) A nervous tumor microenvironment: the impact of adrenergic stress on cancer cells, immunosuppression, and immunotherapeutic response. Cancer immunology, immunotherapy : CII 63 (11):1115-1128. doi:10.1007/s00262-014-1617-9

6. Desborough JP (2000) The stress response to trauma and surgery. British journal of anaesthesia 85 (1):109-117 7. Tai LH, de Souza CT, Belanger S, Ly L, Alkayyal AA, Zhang J, Rintoul JL, Ananth AA, Lam T, Breitbach CJ, Falls TJ, Kirn DH, Bell JC, Makrigiannis AP, Auer RA (2013) Preventing postoperative metastatic disease by inhibiting surgery-induced dysfunction in natural killer cells. Cancer Res 73 (1):97-107. doi:10.1158/00085472.can-12-1993

8. Kang KM, Hong KS, Noh GT, Oh B-Y, Chung SS, Lee R-A, Kim KH (2013) Optimal Time of Initiating Adjuvant Chemotherapy After Curative Surgery in Colorectal Cancer Patients. Annals of Coloproctology 29 (4):150-154. doi:10.3393/ac.2013.29.4.150

9. Kennedy JM, Riji AM (1998) Effects of surgery on the pharmacokinetic parameters of drugs. Clinical pharmacokinetics 35 (4):293-312

10. Nepomniashchikh VA, Lomivorotov VV, Deryagin MN, Kniazkova LG, Novikov MA (2006) Surgical stress and its impact on hepatic metabolism and lipid peroxidation in cardiac patients: P - 119. European Journal of Anaesthesiology (EJA) 23:40-41

11. Shaashua L, Shabat-Simon M, Haldar R, Matzner P, Zmora O, Shabtai M, Sharon E, Allweis T, Barshack I, Hayman L, Arevalo JMG, Ma J, Horowitz M, Cole SW, Ben-Eliyahu S (2017) Perioperative COX-2 and \&amp;beta;-adrenergic blockade improves metastatic biomarkers in breast cancer patients in a phase-II randomized trial. Clinical Cancer Research. doi:10.1158/1078-0432.ccr-17-0152

12. Ceelen WP, Bracke ME Peritoneal minimal residual disease in colorectal cancer: mechanisms, prevention, and treatment. The Lancet Oncology 10 (1):72-79. doi:10.1016/S1470-2045(08)70335-8

13. Lim SH, Spring KJ, de Souza P, MacKenzie S, Bokey L (2015) Circulating tumour cells and circulating nucleic acids as a measure of tumour dissemination in non-metastatic colorectal cancer surgery. European journal of surgical oncology : the journal of the European Society of Surgical Oncology and the British Association of Surgical Oncology 41 (3):309-314. doi:10.1016/j.ejso.2014.12.005

14. Guo N, Lou F, Ma Y, Li J, Yang B, Chen W, Ye H, Zhang J-B, Zhao M-Y, Wu W-J, Shi R, Jones L, Chen KS, Huang XF, Chen S-Y, Liu Y (2016) Circulating tumor DNA detection in lung cancer patients before and after surgery. 6:33519. doi:10.1038/srep33519

https://www.nature.com/articles/srep33519 - supplementary-information

15. Lynch ML, Brand MI (2005) Preoperative Evaluation and Oncologic Principles of Colon Cancer Surgery. Clinics in Colon and Rectal Surgery 18 (3):163-173. doi:10.1055/s-2005-916277

16. (NCCN). NCCN (2016) Rectal Cancer Guidelines.

http://www.nccn.org/professionals/physician gls/pdf/rectal.pdf. . Accessed 17/03/2016 2016 17. Binda MM, Corona R, Amant F, Koninckx PR (2014) Conditioning of the abdominal cavity reduces tumor implantation in a laparoscopic mouse model. Surgery Today 44 (7):1328-1335. doi:10.1007/s00595-014-0832-5 18. Takemoto K, Shiozaki A, Ichikawa D, Komatsu S, Konishi H, Nako Y, Murayama Y, Kuriu Y, Nakanishi M, Fujiwara H, Okamoto K, Sakakura C, Nakahari T, Marunaka Y, Otuji E (2015) Evaluation of the efficacy of peritoneal lavage with distilled water in colorectal cancer surgery: in vitro and in vivo study. Journal of gastroenterology 50 (3):287-297. doi:10.1007/s00535-014-0971-x 
19. Pattana-arun J, Wolff BG (2008) Benefits of povidone-iodine solution in colorectal operations: science or legend. Diseases of the colon and rectum 51 (6):966-971. doi:10.1007/s10350-008-9213-8

20. Alkhamesi NA, Ziprin P, Pfistermuller K, Peck DH, Darzi AW (2005) ICAM-1 Mediated Peritoneal Carcinomatosis, A Target for Therapeutic Intervention. Clinical \& Experimental Metastasis 22 (6):449-459. doi:10.1007/s10585-005-2893-8

21. Andersson B, Ansari D, Nordén M, Nilsson J, Andersson R (2013) Surgical Stress Response After Colorectal Resection. International Surgery 98 (4):292-299. doi:10.9738/INTSURG-D-12-00009.1

22. Brokelman WJA, Lensvelt M, Rinkes IHMB, Klinkenbijl JHG, Reijnen MMPJ (2011) Peritoneal changes due to laparoscopic surgery. Surgical Endoscopy 25 (1):1-9. doi:10.1007/s00464-010-1139-2

23. Jessy T (2011) Immunity over inability: The spontaneous regression of cancer. Journal of natural science, biology, and medicine 2 (1):43-49. doi:10.4103/0976-9668.82318

24. Lippey J, Bousounis R, Behrenbruch C, McKay B, Spillane J, Henderson MA, Speakman D, Gyorki DE (2016) Intralesional PV-10 for in-transit melanoma-A single-center experience. Journal of surgical oncology 114 (3):380384. doi:10.1002/jso.24311

25. Siekmann W, Eintrei C, Magnuson A, Sjolander A, Matthiessen P, Myrelid P, Gupta A (2017) Surgical and not analgesic technique affects postoperative Inflammation following colorectal cancer surgery: a prospective, randomized study. Colorectal disease : the official journal of the Association of Coloproctology of Great Britain and Ireland. doi:10.1111/codi.13643

26. Zawadzki M, Krzystek-Korpacka M, Gamian A, Witkiewicz W (2017) Comparison of inflammatory responses following robotic and open colorectal surgery: a prospective study. International journal of colorectal disease 32 (3):399-407. doi:10.1007/s00384-016-2697-0

27. Shibata J, Ishihara S, Tada N, Kawai K, Tsuno NH, Yamaguchi H, Sunami E, Kitayama J, Watanabe T (2015) Surgical stress response after colorectal resection: a comparison of robotic, laparoscopic, and open surgery. Techniques in coloproctology 19 (5):275-280. doi:10.1007/s10151-014-1263-4 28. Whelan RL, Franklin M, Holubar SD, Donahue J, Fowler R, Munger C, Doorman J, Balli JE, Glass J, Gonzalez JJ, Bessler M, Xie H, Treat M (2003) Postoperative cell mediated immune response is better preserved after laparoscopic vs open colorectal resection in humans. Surg Endosc 17 (6):972-978. doi:10.1007/s00464-001-8263-y 29. Ferri M, Rossi Del Monte S, Salerno G, Bocchetti T, Angeletti S, Malisan F, Cardelli P, Ziparo V, Torrisi MR, Visco V (2013) Recovery of immunological homeostasis positively correlates both with early stages of rightcolorectal cancer and laparoscopic surgery. PLoS One 8 (9):e74455. doi:10.1371/journal.pone.0074455 30. Green BL, Marshall HC, Collinson F, Quirke P, Guillou P, Jayne DG, Brown JM (2013) Long-term follow-up of the Medical Research Council CLASICC trial of conventional versus laparoscopically assisted resection in colorectal cancer. The British journal of surgery 100 (1):75-82. doi:10.1002/bjs.8945

31. Wu FP, Sietses C, von Blomberg BM, van Leeuwen PA, Meijer S, Cuesta MA (2003) Systemic and peritoneal inflammatory response after laparoscopic or conventional colon resection in cancer patients: a prospective, randomized trial. Diseases of the colon and rectum 46 (2):147-155. doi:10.1097/01.dcr.0000049321.18644.08 32. Hill AG, Connolly AB (2006) Minimal access colonic surgery: is it truly minimally invasive? ANZ J Surg 76 (5):282-284. doi:10.1111/j.1445-2197.2006.03711.x

33. Jie H-Y, Ye J-L, Zhou H-H, Li Y-X (2014) Perioperative restricted fluid therapy preserves immunological function in patients with colorectal cancer. World Journal of Gastroenterology : WJG 20 (42):15852-15859. doi:10.3748/wjg.v20.i42.15852

34. Mlecnik B, Bindea G, Kirilovsky A, Angell HK, Obenauf AC, Tosolini M, Church SE, Maby P, Vasaturo A, Angelova M, Fredriksen T, Mauger S, Waldner M, Berger A, Speicher MR, Pages F, Valge-Archer V, Galon J (2016) The tumor microenvironment and Immunoscore are critical determinants of dissemination to distant metastasis. Science translational medicine 8 (327):327ra326. doi:10.1126/scitranslmed.aad6352

35. Heriot AG, Marriott JB, Cookson S, Kumar D, Dalgleish AG (2000) Reduction in cytokine production in colorectal cancer patients: association with stage and reversal by resection. British journal of cancer 82 (5):10091012. doi:10.1054/bjoc. 1999.1034

36. Neeman E, Zmora O, Ben-Eliyahu S (2012) A new approach to reducing post-surgical cancer recurrence: perioperative targeting of catecholamines and prostaglandins. Clinical cancer research : an official journal of the American Association for Cancer Research 18 (18):4895-4902. doi:10.1158/1078-0432.CCR-12-1087 
37. Yakar I, Melamed R, Shakhar G, Shakhar K, Rosenne E, Abudarham N, Page GG, Ben-Eliyahu S (2003) Prostaglandin e(2) suppresses NK activity in vivo and promotes postoperative tumor metastasis in rats. Ann Surg Oncol 10 (4):469-479

38. Ramirez MF, Ai D, Bauer M, Vauthey JN, Gottumukkala V, Kee S, Shon D, Truty M, Kuerer HM, Kurz A, Hernandez M, Cata JP (2015) Innate immune function after breast, lung, and colorectal cancer surgery. The Journal of surgical research 194 (1):185-193. doi:10.1016/j.jss.2014.10.030

39. Donadon M, Hudspeth K, Cimino M, Di Tommaso L, Preti M, Tentorio P, Roncalli M, Mavilio D, Torzilli G (2017) Increased Infiltration of Natural Killer and T Cells in Colorectal Liver Metastases Improves Patient Overall Survival. Journal of Gastrointestinal Surgery. doi:10.1007/s11605-017-3446-6

40. Pugh SA, Harrison RJ, Primrose JN, Khakoo SI (2014) T cells but not NK cells are associated with a favourable outcome for resected colorectal liver metastases. BMC cancer 14:180. doi:10.1186/1471-2407-14-180

41. Brackett CM, Kojouharov B, Veith J, Greene KF, Burdelya LG, Gollnick SO, Abrams SI, Gudkov AV (2016)

Toll-like receptor-5 agonist, entolimod, suppresses metastasis and induces immunity by stimulating an NKdendritic-CD8+ T-cell axis. Proc Natl Acad Sci U S A 113 (7):E874-883. doi:10.1073/pnas.1521359113

42. Dupaul-Chicoine J, Arabzadeh A, Dagenais M, Douglas T, Champagne C, Morizot A, Rodrigue-Gervais IG, Breton V, Colpitts SL, Beauchemin N, Saleh M (2015) The Nlrp3 Inflammasome Suppresses Colorectal Cancer Metastatic Growth in the Liver by Promoting Natural Killer Cell Tumoricidal Activity. Immunity 43 (4):751-763. doi:10.1016/j.immuni.2015.08.013

43. Kee JY, Ito A, Hojo S, Hashimoto I, Igarashi Y, Tsukada K, Irimura T, Shibahara N, Nakayama T, Yoshie O, Sakurai H, Saiki I, Koizumi K (2013) Chemokine CXCL16 suppresses liver metastasis of colorectal cancer via augmentation of tumor-infiltrating natural killer T cells in a murine model. Oncology reports 29 (3):975-982. doi:10.3892/or.2012.2185

44. Weese JL, Emoto SE, Sondel PM (1987) Reduced incidence of hepatic metastases by perioperative treatment with recombinant human interleukin-2. Diseases of the colon and rectum 30 (7):503-507

45. Shakhar G, Ben-Eliyahu S (2003) Potential prophylactic measures against postoperative immunosuppression: could they reduce recurrence rates in oncological patients? Ann Surg Oncol 10 (8):972-992

46. Nichols PH, Ramsden CW, Ward U, Sedman PC, Primrose JN (1992) Perioperative Immunotherapy with Recombinant Interleukin 2 in Patients Undergoing Surgery for Colorectal Cancer. Cancer Research 52 (20):57655769

47. Brivio F, Fumagalli L, Chiarelli M, Denova M, Bertolini A, Cetta M, Nespoli A (2007) [Immunotherapy in radical surgery of colorectal carcinoma]. Chirurgia italiana 59 (5):635-640

48. Tai LH, Zhang J, Auer RC (2013) Preventing surgery-induced NK cell dysfunction and cancer metastases with influenza vaccination. Oncoimmunology 2 (11):e26618. doi:10.4161/onci.26618

49. Neeman E, Ben-Eliyahu S (2013) The perioperative period and promotion of cancer metastasis: New outlooks on mediating mechanisms and immune involvement. Brain, behavior, and immunity 30 (Suppl):S32-S40.

doi:10.1016/j.bbi.2012.03.006

50. Sorski L, Melamed R, Matzner P, Lavon H, Shaashua L, Rosenne E, Ben-Eliyahu S (2016) Reducing liver metastases of colon cancer in the context of extensive and minor surgeries through beta-adrenoceptors blockade and COX2 inhibition. Brain Behav Immun 58:91-98. doi:10.1016/j.bbi.2016.05.017

51. Coelho M, Soares-Silva C, Brandao D, Marino F, Cosentino M, Ribeiro L (2017) beta-Adrenergic modulation of cancer cell proliferation: available evidence and clinical perspectives. Journal of cancer research and clinical oncology 143 (2):275-291. doi:10.1007/s00432-016-2278-1

52. Masur K, Niggemann B, Zanker KS, Entschladen F (2001) Norepinephrine-induced migration of SW 480 colon carcinoma cells is inhibited by beta-blockers. Cancer Res 61 (7):2866-2869

53. Chin CC, Li JM, Lee KF, Huang YC, Wang KC, Lai HC, Cheng CC, Kuo YH, Shi CS (2016) Selective beta2AR Blockage Suppresses Colorectal Cancer Growth Through Regulation of EGFR-Akt/ERK1/2 Signaling, G1Phase Arrest, and Apoptosis. J Cell Physiol 231 (2):459-472. doi:10.1002/jcp.25092

54. Barron TI, Sharp L, Visvanathan K (2012) Beta-adrenergic blocking drugs in breast cancer: a perspective review. Therapeutic Advances in Medical Oncology 4 (3):113-125. doi:10.1177/1758834012439738

55. Benish M, Bartal I, Goldfarb Y, Levi B, Avraham R, Raz A, Ben-Eliyahu S (2008) Perioperative Use of $\beta$ blockers and COX-2 Inhibitors May Improve Immune Competence and Reduce the Risk of Tumor Metastasis. Annals of surgical oncology 15 (7):10.1245/s10434-10008-19890-10435. doi:10.1245/s10434-008-9890-5 
56. Caine GJ, Stonelake PS, Lip GY, Kehoe ST (2002) The hypercoagulable state of malignancy: pathogenesis and current debate. Neoplasia 4 (6):465-473. doi:10.1038/sj.neo.7900263

57. Castell JV, Gomez-Lechon MJ, David M, Andus T, Geiger T, Trullenque R, Fabra R, Heinrich PC (1989)

Interleukin-6 is the major regulator of acute phase protein synthesis in adult human hepatocytes. FEBS letters 242

(2):237-239

58. Levi M, Keller TT, van Gorp E, ten Cate H (2003) Infection and inflammation and the coagulation system.

Cardiovascular research 60 (1):26-39

59. Bleeker JS, Hogan WJ (2011) Thrombocytosis: diagnostic evaluation, thrombotic risk stratification, and riskbased management strategies. Thrombosis 2011:536062. doi:10.1155/2011/536062

60. Seth R, Tai LH, Falls T, de Souza CT, Bell JC, Carrier M, Atkins H, Boushey R, Auer RA (2013) Surgical stress promotes the development of cancer metastases by a coagulation-dependent mechanism involving natural killer cells in a murine model. Ann Surg 258 (1):158-168. doi:10.1097/SLA.0b013e31826fcbdb

61. Gay LJ, Felding-Habermann B (2011) Contribution of platelets to tumour metastasis. Nat Rev Cancer 11

(2):123-134

62. Coyle C, Cafferty FH, Rowley S, MacKenzie M, Berkman L, Gupta S, Pramesh CS, Gilbert D, Kynaston H, Cameron D, Wilson RH, Ring A, Langley RE, Add-Aspirin i (2016) ADD-ASPIRIN: A phase III, double-blind, placebo controlled, randomised trial assessing the effects of aspirin on disease recurrence and survival after primary therapy in common non-metastatic solid tumours. Contemporary Clinical Trials 51:56-64.

doi:10.1016/j.cct.2016.10.004

63. Gottschalk A, Sharma S, Ford J, Durieux ME, Tiouririne M (2010) Review article: the role of the perioperative period in recurrence after cancer surgery. Anesthesia and analgesia 110 (6):1636-1643.

doi:10.1213/ANE.0b013e3181de0ab6

64. Melamed R, Bar-Yosef S, Shakhar G, Shakhar K, Ben-Eliyahu S (2003) Suppression of natural killer cell activity and promotion of tumor metastasis by ketamine, thiopental, and halothane, but not by propofol: mediating mechanisms and prophylactic measures. Anesthesia and analgesia 97 (5):1331-1339

65. Ahlers O, Nachtigall I, Lenze J, Goldmann A, Schulte E, Hohne C, Fritz G, Keh D (2008) Intraoperative thoracic epidural anaesthesia attenuates stress-induced immunosuppression in patients undergoing major abdominal surgery. British journal of anaesthesia 101 (6):781-787. doi:10.1093/bja/aen287

66. Heaney A, Buggy DJ (2012) Can anaesthetic and analgesic techniques affect cancer recurrence or metastasis? British journal of anaesthesia 109 Suppl 1:i17-i28. doi:10.1093/bja/aes421

67. Patel S, Lutz JM, Panchagnula U, Bansal S (2012) Anesthesia and perioperative management of colorectal surgical patients - A clinical review (Part 1). Journal of Anaesthesiology, Clinical Pharmacology 28 (2):162-171. doi:10.4103/0970-9185.94831

68. Das J, Kumar S, Khanna S, Mehta Y (2014) Are we causing the recurrence-impact of perioperative period on long-term cancer prognosis: Review of current evidence and practice. Journal of Anaesthesiology, Clinical Pharmacology 30 (2):153-159. doi:10.4103/0970-9185.129996

69. Atzil S, Arad M, Glasner A, Abiri N, Avraham R, Greenfeld K, Rosenne E, Beilin B, Ben-Eliyahu S (2008)

Blood Transfusion Promotes Cancer Progression: A Critical Role for Aged Erythrocytes. Anesthesiology 109 (6):989-997. doi:10.1097/ALN.0b013e31818ddb72

70. Sajid MS, Mallick AS, Rimpel J, Bokari SA, Cheek E, Baig MK (2008) Effect of heated and humidified carbon dioxide on patients after laparoscopic procedures: a meta-analysis. Surgical laparoscopy, endoscopy \& percutaneous techniques 18 (6):539-546. doi:10.1097/SLE.0b013e3181886ff4

71. Mari G, Crippa J, Costanzi A, Mazzola M, Rossi M, Maggioni D (2016) ERAS Protocol Reduces IL-6 Secretion in Colorectal Laparoscopic Surgery: Results From a Randomized Clinical Trial. Surgical laparoscopy, endoscopy \& percutaneous techniques 26 (6):444-448. doi:10.1097/sle.0000000000000324

72. Mari G, Costanzi A, Crippa J, Falbo R, Miranda A, Rossi M, Berardi V, Maggioni D (2016) Surgical Stress Reduction in Elderly Patients Undergoing Elective Colorectal Laparoscopic Surgery within an ERAS Protocol. Chirurgia (Bucharest, Romania : 1990) 111 (6):476-480. doi:10.21614/chirurgia.111.6.476

73. Lee J-W, Shahzad MMK, Lin YG, Armaiz-Pena G, Han H-D, Kim H-S, Nam EJ, Jennings NB, Halder J, Mangala LS, Nick AM, Stone RL, Lu C, Lutgendorf SK, Cole SW, Lokshin AE, Sood AK (2009) Surgical Stress Promotes Tumor Growth in Ovarian Carcinoma. Clinical cancer research : an official journal of the American Association for Cancer Research 15 (8):2695-2702. doi:10.1158/1078-0432.CCR-08-2966 
74. Tai L-H, Tanese de Souza C, Sahi S, Zhang J, Alkayyal AA, Ananth AA, Auer RAC (2014) A Mouse Tumor Model of Surgical Stress to Explore the Mechanisms of Postoperative Immunosuppression and Evaluate Novel Perioperative Immunotherapies. Journal of visualized experiments : JoVE (85):51253. doi:10.3791/51253 75. Choy C, Raytis JL, Smith DD, Duenas M, Neman J, Jandial R, Lew MW (2016) Inhibition of beta2-adrenergic receptor reduces triple-negative breast cancer brain metastases: The potential benefit of perioperative beta-blockade. Oncology reports 35 (6):3135-3142. doi:10.3892/or.2016.4710

76. Pisco AO, Huang S (2015) Non-genetic cancer cell plasticity and therapy-induced stemness in tumour relapse: 'What does not kill me strengthens me'. British journal of cancer 112:1725. doi:10.1038/bjc.2015.146

77. Almendro V, Kim HJ, Cheng YK, Gonen M, Itzkovitz S, Argani P, van Oudenaarden A, Sukumar S, Michor F, Polyak K (2014) Genetic and phenotypic diversity in breast tumor metastases. Cancer Res 74 (5):1338-1348. doi:10.1158/0008-5472.can-13-2357-t

78. Meacham CE, Morrison SJ (2013) Tumour heterogeneity and cancer cell plasticity. Nature 501 (7467):328-337. doi:10.1038/nature12624

79. Kreso A, Dick John E Evolution of the Cancer Stem Cell Model. Cell Stem Cell 14 (3):275-291. doi:10.1016/j.stem.2014.02.006

80. Kim K-T, Lee HW, Lee H-O, Kim SC, Seo YJ, Chung W, Eum HH, Nam D-H, Kim J, Joo KM, Park W-Y (2015) Single-cell mRNA sequencing identifies subclonal heterogeneity in anti-cancer drug responses of lung adenocarcinoma cells. Genome biology 16 (1):127. doi:10.1186/s13059-015-0692-3

81. Weber K, Thomaschewski M, Benten D, Fehse B (2012) RGB marking with lentiviral vectors for multicolor clonal cell tracking. Nat Protocols 5 (4):839-849

82. Kakumoto M, Sakaeda T, Takara K, Nakamura T, Kita T, Yagami T, Kobayashi H, Okamura N, Okumura K (2003) Effects of carvedilol on MDR1-mediated multidrug resistance: comparison with verapamil. Cancer science 94 (1):81-86

83. Bachmakov I, Werner U, Endress B, Auge D, Fromm MF (2006) Characterization of beta-adrenoceptor antagonists as substrates and inhibitors of the drug transporter P-glycoprotein. Fundamental \& clinical pharmacology 20 (3):273-282. doi:10.1111/j.1472-8206.2006.00408.x

84. Yang WL, Frucht H (2000) Cholinergic receptor up-regulates COX-2 expression and prostaglandin E(2) production in colon cancer cells. Carcinogenesis 21 (10):1789-1793

85. Li M, Tan SY, Wang XF (2014) Paeonol exerts an anticancer effect on human colorectal cancer cells through inhibition of PGE(2) synthesis and COX-2 expression. Oncology reports 32 (6):2845-2853.

doi:10.3892/or.2014.3543

86. Cervantes-Madrid DL, Nagi S, Asting Gustafsson A (2017) FosB transcription factor regulates COX-2 expression in colorectal cancer cells without affecting PGE2 expression. Oncology letters 13 (3):1411-1416. doi:10.3892/ol.2017.5571

87. Demicheli R, Retsky MW, Hrushesky WJ, Baum M, Gukas ID (2008) The effects of surgery on tumor growth: a century of investigations. Ann Oncol 19 (11):1821-1828. doi:10.1093/annonc/mdn386

88. Coelho M, Moz M, Correia G, Teixeira A, Medeiros R, Ribeiro L (2015) Antiproliferative effects of betablockers on human colorectal cancer cells. Oncology reports 33 (5):2513-2520. doi:10.3892/or.2015.3874 89. Wong HP, Ho JW, Koo MW, Yu L, Wu WK, Lam EK, Tai EK, Ko JK, Shin VY, Chu KM, Cho CH (2011) Effects of adrenaline in human colon adenocarcinoma HT-29 cells. Life sciences 88 (25-26):1108-1112. doi:10.1016/j.lfs.2011.04.007

90. Lin Q, Wang F, Yang R, Zheng X, Gao H, Zhang P (2013) Effect of chronic restraint stress on human colorectal carcinoma growth in mice. PLoS One 8 (4):e61435. doi:10.1371/journal.pone.0061435

91. Grillet F, Bayet E, Villeronce O, Zappia L, Lagerqvist EL, Lunke S, Charafe-Jauffret E, Pham K, Molck C, Rolland N, Bourgaux JF, Prudhomme M, Philippe C, Bravo S, Boyer JC, Canterel-Thouennon L, Taylor GR, Hsu A, Pascussi JM, Hollande F, Pannequin J (2016) Circulating tumour cells from patients with colorectal cancer have cancer stem cell hallmarks in <em>ex vivo</em> culture. Gut. doi:10.1136/gutjnl-2016-311447

\section{Material \& Methods:}




\section{Cells and reagents}

CPP35 are patient-derived colorectal cancer cells established from fresh primary tumour of the transverse colon biopsies isolated from a treatment-naïve 81 year old male (human ethics agreement \#2011-A01141-100 40, Nimes University Hospital, France)[75]. The cells were grown in Dulbecco's Modified Eagles Medium (Gibco) supplemented with 10\% fetal bovine serum (US; Invitrogen, lot: 16000044), 1\% Pen/Strep (100 U/ml penicillin, 100 $\mu \mathrm{g} / \mathrm{ml}$ streptomycin, Life Technologies), $1 \%$ Glutamax (Life Technologies). Cells were maintained at $37^{\circ} \mathrm{C}$ in a humidified $95 \%$ air $/ 5 \% \mathrm{CO}_{2}$ atmosphere. Isoproterenol, Celecoxib and Propranolol were kind gifts from Dr. E. Sloan.

\section{Generation of CRC LeGO cells}

The CPP35-LeGO cell line was generated as previously described in Weber et al. (2012). In brief, CPP35 cells were transduced with plasmids of lentiviral vectors encoding for three different RGB fluorescent proteins: LeGO-Cer2 (Cerulean; Addgene plasmid 27338, Addgene); LeGO-C2 (mCherry; Addgene plasmid 27339, Addgene); LeGO-V2 (Venus; Addgene plasmid 27340, Addgene).

\section{LeGO cell imaging}

For cell growth and motility assays (cf below), images were composed of individual measurements across three fluorescence channels at 50\% excitation alongside a fourth digital phase contrast channel. Cell segmentation was performed using the inbuilt "Method P", which utilises the Digital Phase Contrast channel. Following optimisation, the splitting coefficient and common threshold values were set at 0.8 and 0.5 , respectively. For our purposes, a cell was defined as an entity with an area greater than $300 \mu \mathrm{m}^{2}$.

\section{Cell growth assay}

Cells were trypsinised, harvested and seeded onto 96-well flat-bottom plates at a density of 4,000 cells/well, then incubated at $37^{\circ} \mathrm{C}$ for $24 \mathrm{~h}$ in DMEM supplemented with $10 \% \mathrm{FBS}$. Subsequent to adding Isoproterenol $(1 \mu \mathrm{M})$, Celecoxib $(1 \mu \mathrm{M})$ and Propranolol $(10 \mu \mathrm{M})$, the cells were cultured at $37^{\circ} \mathrm{C}$ in DMEM supplemented with $1 \%$ FBS for a further $72 \mathrm{~h}$. Cell density was assessed used the Operetta High Content Imaging System fluorescent microscope (PerkinElmer, Santa Clara, CA, USA). Acquisitions were performed immediately after treatment, at $12 \mathrm{~h}$, at $24 \mathrm{~h}$ and at $48 \mathrm{~h}$ under a $\times 20$ objective (LWD HH12000504) using 35 fields of view per well $\left(1351 \times 1017 \mu \mathrm{m}^{2} /\right.$ field). The number of cells remaining at each time point was quantified by the Harmony software (PerkinElmer, Santa Clara, CA, USA).

\section{Motility assay}

CPP35-LeGO cells were plated on a clear-bottom back 96-well plate (COR3603, InVitro Technologies) at a density of 50,000 cells/well in DMEM supplemented with 10\% FBS. The monolayers were scratched manually with a sterile pipette tip, and treated with Isoproterenol $(1 \mu \mathrm{M})$, Celecoxib $(1 \mu \mathrm{M})$, Propranolol $(10 \mu \mathrm{M})$ or a combination of Celecoxib/Propranolol ( $1 \mu \mathrm{M} / 10 \mu \mathrm{M}$ respectively) in DMEM supplemented with $1 \%$ FBS and incubated at $37^{\circ} \mathrm{C}$. Image acquisitions using the Operetta High Content Imaging System were performed every 24 hours under a × 10 objective (LWD HH12000504) using 5 fields of view $\left(1351 \times 1017 \mu^{2} /\right.$ field $)$ selected along the scratch. At each timepoint, images were acquired at 5 minute intervals for a duration of 30 minutes, yielding a series of 6 images across which the speed of migration and the direction of movement of the cells were evaluated using the Harmony software (PerkineElmer, Santa Clara, CA, USA).

\section{Data Curation and RGB Clustering}

LeGO-cells were clustered according to their fluorescence intensity for each of the three fluorescent channels; Cerulean, Venus and mCherry. The cluster thresholds were determined based on the intensity frequency distributions of the vehicle-treated cells at the final time point using GraphPad Prism. The cells were thus divided into four clusters for each fluorescent channel, annotated using the following code: " 1 " corresponds to the $<25 \%$ quartile, " 2 " corresponds to the $25-50 \%$ quartile, " 3 " corresponds to the $50-75 \%$ quartile, and " 4 " corresponds to the $>75 \%$ quartile. Combining the cluster codes for three fluorescent channels results in a 3 digit code arranged in the 
order: Cerulean-Venus-mCherry. A cell with the cluster code 123 would thus have an intensity in the $<25 \%$ quartile for Cerulean, $25-50 \%$ for Venus, and $>75 \%$ for mCherry. In order to take into account the minor natural variations in intensities that can occur across experiments, the thresholds were set for each individual experiment.

Statistical analysis

All statistical analyses were performed using GraphPad Prism software. Data is expressed as mean $+/$ - standard deviation (SD) or mean $+95 \%$ confidence interval as indicated, from three independent measurements. The minimum threshold for rejecting the null hypothesis was $\mathrm{p}<0.05$. 


\section{Figure 2}

Heterogeneous growth response to pharmacological $\beta$-Adrenergic Receptor and/or Cyclooxygenase-2 modulators in RGB-tagged cells.

a

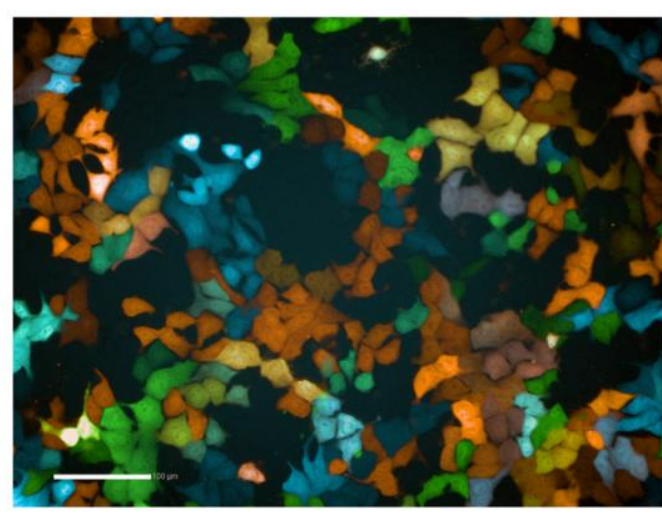

C

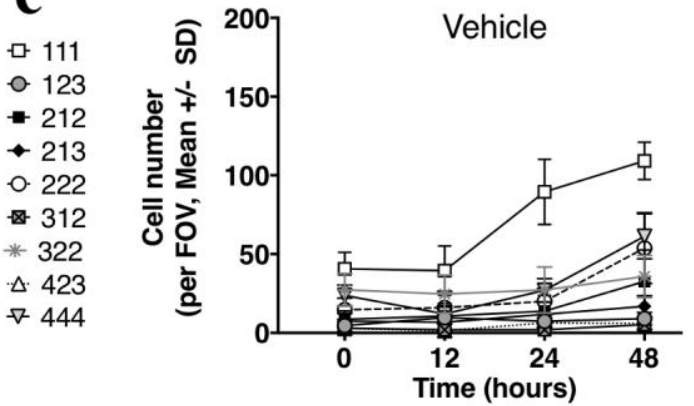

$\mathbf{e}$

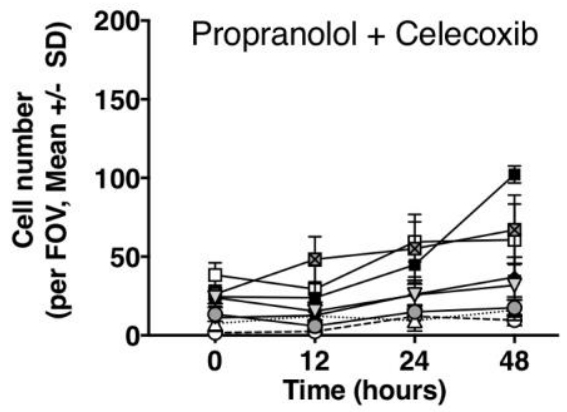

b

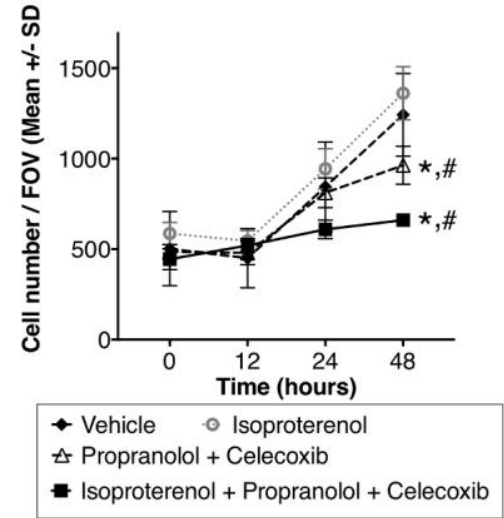

d

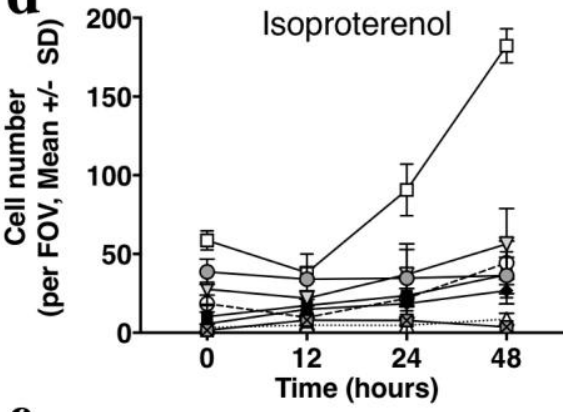

Isoproterenol +

$\mathbf{f}$

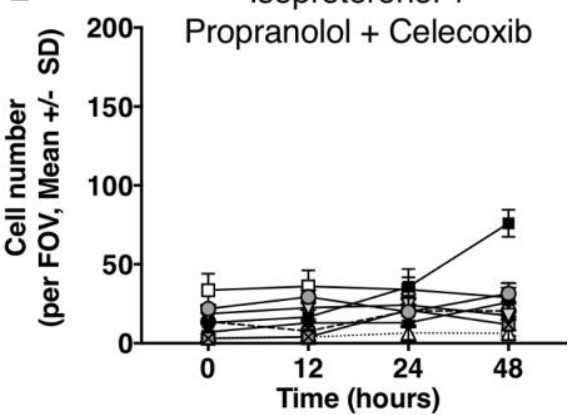




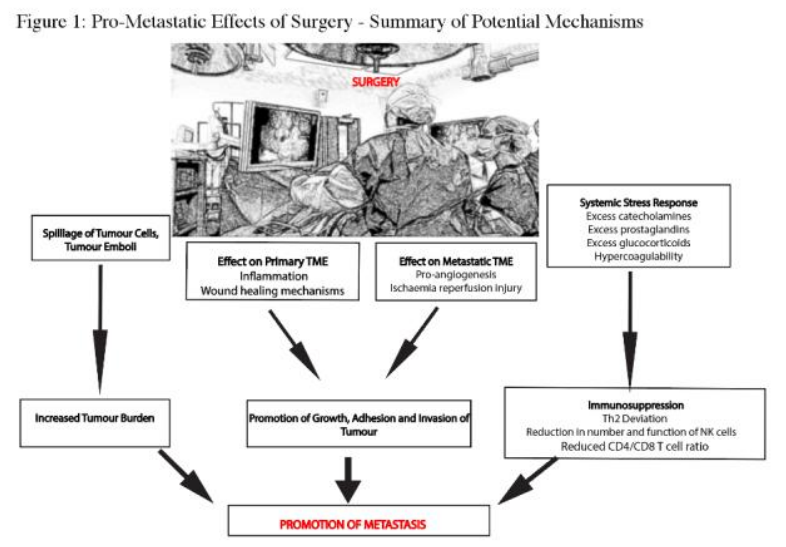

TME = Tumor microenvironment, $\mathrm{NK}=$ Natural Killer Cells

\section{Figure 3}

Heterogeneous motility response to pharmacological $\beta$-Adren
and/or Cyclooxygenase- 2 modulators in RGB-tagged
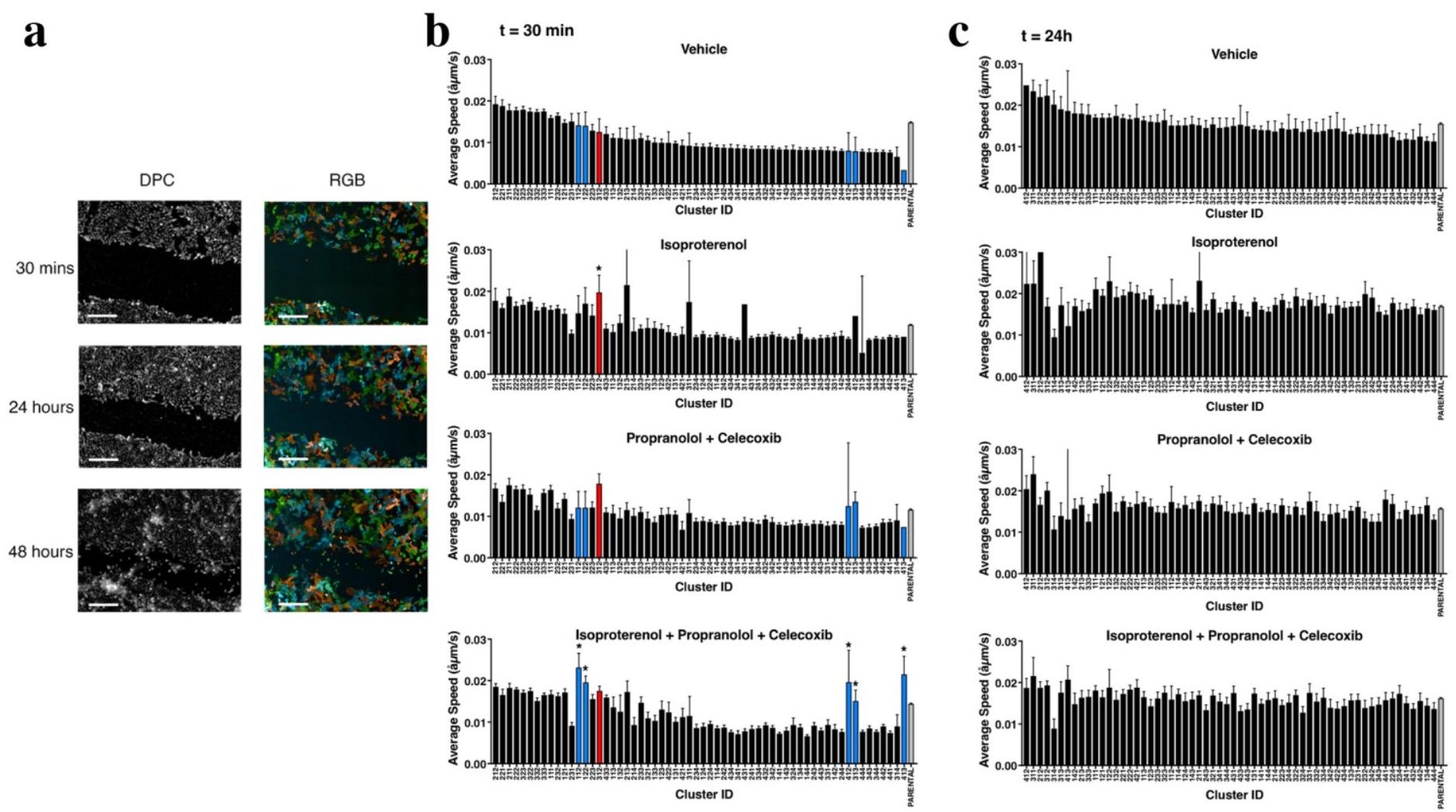


\section{University Library}

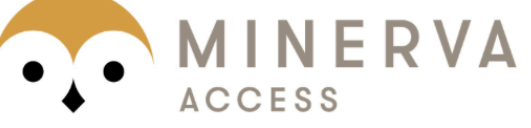

A gateway to Melbourne's research publications

Minerva Access is the Institutional Repository of The University of Melbourne

Author/s:

Behrenbruch, C;Shembrey, C;Paquet-Fifield, S;Molck, C;Cho, H-J;Michael, M;Thomson, BNJ;Heriot, AG;Hollande, $F$

Title:

Surgical stress response and promotion of metastasis in colorectal cancer: a complex and heterogeneous process

Date:

2018-04-01

Citation:

Behrenbruch, C., Shembrey, C., Paquet-Fifield, S., Molck, C., Cho, H. -J., Michael, M., Thomson, B. N. J., Heriot, A. G. \& Hollande, F. (2018). Surgical stress response and promotion of metastasis in colorectal cancer: a complex and heterogeneous process. CLINICAL \& EXPERIMENTAL METASTASIS, 35 (4), pp.333-345. https://doi.org/10.1007/ s10585-018-9873-2.

Persistent Link:

http://hdl.handle.net/11343/282669 